\title{
Testimony method to ameliorate post-traumatic
}

\section{stress symptoms}

\author{
Community-based intervention study with Mozambican \\ civil war survivors
}

\section{VICTOR IGREJA, WIM C. KLEIJN, BAS J. N. SCHREUDER, JANIE A. VAN DIJK and MARGOT VERSCHUUR}

\section{Background The effectiveness of the testimony method has not been \\ established in rural communities with survivors of prolonged civil war.}

Aims To examine the effectiveness and feasibility of a testimony method to ameliorate post-traumatic stress symptoms.

Method Participants $(n=206)$

belonged to former war zones in Mozambique. They were divided into a case ( $n=137)$ and a non-case group $(n=69)$. The case group was randomly divided into an intervention $(n=66)$ and a control group ( $n=7 \mathrm{I})$. Symptoms were measured during baseline assessment, postintervention and at an II-month follow-up.

Results Post-intervention measurements demonstrated significant symptom reduction in both the intervention and the control group. No significant differences were found between the intervention and the control group. Follow-up measurements showed sustained lower levels of symptoms in both groups, and some indications of a positive intervention effect in women.

\section{Conclusions A remarkable drop in} symptoms could not be linked directly to the intervention. Feasibility of the intervention was good, but controlling the intervention in a small rural community appeared to be a difficult task to accomplish.

Declaration of interest None. This study was partly funded by Associação Esperança ParaTodos, Mozambique.
A literature review of 135 epidemiological studies on the prevalence of post-traumatic stress disorder (PTSD) showed that only $6 \%$ were situated in developing countries (de Girolamo \& McFarlane, 1996). The recent history of Mozambique is characterised by almost three decades of war, and a recent study showed that 5 years after this war $63 \%$ of the study participants suffered from high levels of psychiatric symptoms (Schreuder et al, 2001). Governmental authorities in post-conflict countries in Africa, along with the World Health Organization, regularly address these problems but there are almost no studies on the merits of interventions aimed at the post-traumatic symptoms among this population (World Health Organization, 2002). In circumstances where scarcity of mental health care resources is the rule, the testimony method of psychotherapy potentially could be valuable. The testimony method is a variant of a trauma exposure technique and it is relatively easy to master, is brief and does not require sophisticated materials. Trauma survivors are invited to tell the story of their traumatic experiences and, together with the interviewer, they create a narrative document of these experiences (Weine et al, 1998). The act of constructing a coherent trauma story helps the survivor to function. The method has been used with survivors of state-sponsored violence in particular (Cienfuegos \& Monelli, 1983; Weine et al, 1998). The literature on similar exposure treatment techniques applied with other types of trauma victims shows effectiveness in ameliorating PTSD (Foa et al, 1995; Van der Kolk et al, 1996). The objectives of this study were to examine the effectiveness of the testimony method in reducing post-traumatic stress symptoms in survivors of civil war and to examine the feasibility of the testimony method in a rural, impoverished, war-stricken African population.

\section{METHOD}

\section{General procedure}

This study, to evaluate the effectiveness of the testimony method, was an extension of a previous investigation in rural and central Mozambique into how survivors dealt with the memories of the civil war (Schreuder et al, 2001). To introduce the study, public meetings were held with the official and traditional authorities of two villages (Mucodza and Casa Banana) and the targeted populations. In each of the villages it was explained that this study would have different phases: every participant would be interviewed in his or her household; selected participants would be invited to tell their traumatic experiences in depth; and everyone would be visited again twice for an assessment, 2 and 11 months after the first interview. At the participants' request, it was agreed that the assessment visits could also take place in their fields (machambas), particularly during the harvest period. Having clarified the purpose of the study and the procedures to be followed, the illiterate inhabitants gave their verbal consent to participate in this study.

\section{Sampling strategy}

The inhabitants belong to a community where agriculture is the main activity. In general, the man is the head of the household, has one or more wives and is responsible for family-related issues. Inclusion criteria were: adult men or women; born in the region; and having survived the war while living within the regional war zones. Former refugees or displaced persons from other regions were excluded. In both villages, household surveys were conducted. Because the villages are small, each eligible household was included during the baseline measurements.

During the baseline measurements every participant was given a consecutive number. By using a cut-off point in the measurements of post-traumatic stress symptoms, the group was divided into a case $(n=137)$ and a non-case group $(n=69)$ (see Assessments). Depending on whether their number was an even or odd one, participants belonging to the case group were respectively assigned to an intervention group $(n=66)$ or a control group $(n=71)$. During the study, five participants died and four moved to other locations. The level of commitment to our 
study was very satisfactory and $95 \%$ of all participants took part in all four assessment phases.

\section{Intervention design}

The study was conducted in the ChiGorongose language in collaboration with three native speakers acting as interpreters (two men and one woman). The interpreter used was always the same gender as the survivor. The testimonies were written in note form, and the interviewer (V.I.) read the testimony back to the participant in order to produce an accurate final version.

After explaining the testimony procedure to the participant, the following topics were covered:

(a) one major traumatic experience that the person went through;

(b) the facts concerning this event (time, place, duration and people involved);

(c) the person's role during the event (observer, participant, active or passive);

(d) detailed description of the event;

(e) the individual and social dimensions of the experience;

(f) perceptions and feelings at the time of the event;

(g) perceptions and feelings at the time of the testimony telling;

(h) the relationship between the experience and the present situation;

(i) feelings about the future (individual, family and community).

The testimony intervention was only applied to the intervention group $(n=66)$; the control group did not receive any particular intervention. All testimonies were given in the household of the participants, and in general they consisted of only one session lasting about $60 \mathrm{~min}$. With seven participants $(11 \%)$ a second session was necessary to complete the testimony procedure. In this way it took about 8 weeks in total to expose all participants of this group to the intervention.

\section{Assessments}

Data were collected using standardised instruments and consisted of five sections: demographic data and war circumstances (9 items); psychiatric morbidity as measured by the Self-Report Questionnaire (SRQ: 26 items; Harding et al, 1980); shocking experiences measured by a section of the Harvard Trauma Questionnaire
(HTQ: 24 items; Mollica et al, 1996); prevalence of nightmares assessed with the Nocturnal Intrusions after Traumatic Experiences questionnaire (NITE: 12 items; Schreuder et al, 2000); and post-traumatic stress symptoms as measured with the Self-Inventory for PTSD (SIFP: 22 items; Hovens et al, 2001).

The SRQ is a psychiatric screening instrument designed by the World Health Organization Collaborative Studies for Extending Mental Health Care; it was validated in a non-Western population and has been used subsequently in numerous studies in different non-Western societies (Deshpande et al, 1989; Bhagwanjee et al, 1998). Because the SRQ was used as a scale in this study (and not as a screening instrument), Cronbach's $\alpha$ coefficients were calculated as measures of reliability. In the population studied, they scored a satisfactory 0.82 for the neurosis sub-scale (SRQ-20) and a rather low 0.46 for the psychotism sub-scale. The latter sub-scale showed a very skewed distribution of scores: $53 \%$ of participants had none of these symptoms and $25 \%$ reported only one. Because of these psychometric properties, this sub-scale was not used in the analyses.

The trauma event section of the HTQ consists of 17 named events that can be checked as 'experienced', 'witnessed', 'heard of' or 'no'. The HTQ was developed by Mollica and co-workers and originally validated for use in a non-Western population (mainly refugees from East Asia) (Mollica et al, 1996). The HTQ subsequently has been used in research with refugees from very different regions of the world (Kleijn et al, 2001). Seven items that were appropriate for the experiences in the region under study were added (see Table 2).

The NITE consists of 11 questions on different aspects of nightmares, to be answered only if nightmares have occurred in the past 4 weeks (using a 'yes' or 'no' format), and one open question asking for a description of such a nightmare. Although the NITE is in use in studies with nonWestern refugee patients, only data on Western populations have been reported until now (Schreuder et al, 2000). In this study the NITE is used essentially as a structured method for gathering the impact of nightmares (Cronbach's $\alpha$ coefficient in this study group: 0.73 ).

The SIFP measures symptoms according to the DSM-IV (American Psychiatric Association, 1994) classification of PTSD.
Items are answered in a Likert-scale format (1='not at all', 2='slightly', 3='seriously' and 4='extremely'). Reliability data have been published only for Western populations, with Cronbach's $\alpha$ coefficients ranging from 0.92 (total) to, respectively, $0.83,0.86$ and 0.79 for the intrusion, avoidance and hyperarousal sub-scales (Hovens et al, 2001). Similarly, these coefficients were calculated in our study population, showing a coefficient of 0.86 for the total SIFP scale and, respectively, $0.87,0.71$ and 0.71 for the intrusion, avoidance and hyperarousal sub-scales.

Because the participants in the study were illiterate, all questions from these instruments were applied within structured interviews. The validation process of these interviews was carried out during pilot studies (1997 and 1998). Linguistic equivalents for each of the items on the questionnaire were established in Portuguese and Chi-Gorongose. All questionnaires were first translated from English into Portuguese and then into the local language by bilingual members of Gorongosa. The translations were then translated back into Portuguese by different interpreters into a quasi-final version (as the study progressed, we discovered that some previously translated concepts needed adjustment). The validation process confirmed that some items were not valid for our sample because of either semantic problems or contextual irrelevance. On the basis of this preliminary analysis, three items had to be removed from the PTSD questionnaire: 'acting as if past events were happening again', 'avoidance of situations' and 'not being able to recall important aspects of past events'. Consequently, the initial cut-off point score required to classify a participant as a case or non-case (total score $\geqslant 52$ ) was replaced by a cut-off point score of $\geqslant 46$.

\section{Data analysis}

Our working hypothesis was stated as: 'Compared with baseline levels of symptoms, levels will be relatively lower in a group that received the intervention, as compared with the levels found in a control group'. Because symptoms were measured by instruments validated in other countries, reliability analyses were initially carried out on the scales of the three standardised assessment instruments (SRQ, SIFP and NITE), on data based on the baseline measurements. After gathering post-intervention 
measurements from all participants of the control and intervention groups, postintervention scale scores were calculated and the data analysis was started.

Differences between baseline and postintervention measurements were analysed by paired-sample $t$-tests for each scale and group. The main differences between the intervention and control groups, and the eventual interaction effects with the background variable (gender), were analysed by means of a two-way analysis of covariance with repeated measurements, using the scales of the SRQ, SIFP and NITE as the dependent variables and 'number of shocking experiences' as a covariate.

After adding the 11-month follow-up data, long-term effects were analysed by comparing post-intervention and followup measurements using paired-sample $t$ tests. To analyse follow-up intervention effects, the multivariate model (as used in the analysis of post-intervention outcomes) was applied, with baseline and follow-up measurements as dependent variables. Chi-squared tests were used for post hoc comparisons of reported anxiety dreams.

In general, statistical significance was defined as $P<0.05$ (two-sided).

\section{RESULTS}

\section{Demographic characteristics and war circumstances}

Table 1 gives a summary of gender distribution, age, family size, numbers of living and deceased children and war circumstances. Figures on age are approximate $($ mean $=40.2$, s.d. $=14.1)$. Many participants did not know their date of birth, so age had to be determined in a negotiation process through association with important events that could be remembered.

Marital status differed for men and women: most of the men were married with one $(57 \%)$ or more wives $(39 \%)$; of the women, $64 \%$ reported that they were married and $32 \%$ indicated a widowed state. The mean number of family members in each household was 6.2 (s.d.=3.4), of which living children represented a mean number of 3.8 (s.d.=2.4). In many households, children had died of illness (mean number $=2.9$, s.d. $=2.6$ ).

Comparison of the intervention and control group with the non-case group (all other participants) with regard to these demographic characteristics did not reveal significant differences, and neither did
Table I Demographic and background characteristics

\begin{tabular}{lcccc}
\hline & $\begin{array}{c}\text { All } \\
\text { participants } \\
(n=206)\end{array}$ & $\begin{array}{c}\text { Control } \\
\text { group } \\
(n=7 I)\end{array}$ & $\begin{array}{c}\text { Intervention } \\
\text { group } \\
(n=66)\end{array}$ & $\begin{array}{c}\text { Non-case } \\
\text { group } \\
(n=69)\end{array}$ \\
\hline Gender, $n$ (\%) & & & & \\
$\quad$ Men & $115(56)$ & $38(54)$ & $39(59)$ & $38(55)$ \\
$\quad$ Women & $91(44)$ & $33(46)$ & $27(4 I)$ & $31(45)$ \\
Age (years), mean (s.d.) & $40.2(14.1)$ & $39.1(13.9)$ & $40.7(13.4)$ & $40.8(15.1)$ \\
Family size (persons), mean (s.d.) & $6.2(3.4)$ & $6.1(3.5)$ & $5.9(3.5)$ & $6.6(3.0)$ \\
Children (living), mean (s.d.) & $3.8(2.4)$ & $3.6(2.4)$ & $3.8(2.4)$ & $4.0(2.5)$ \\
Children (died of illness), mean (s.d.) & $2.9(2.6)$ & $2.9(2.7)$ & $2.6(2.5)$ & $3.5(2.8)$ \\
War-zone (years), mean (s.d.) & $15.6(2.0)$ & $15.8(I .0)$ & $15.5(2.0)$ & $15.5(2.7)$ \\
\hline
\end{tabular}

comparison of the intervention group with the control group, so all participants belonged to a relatively homogeneous population.

\section{Traumatic experiences}

Table 2 presents the types of traumatic events that were reported. All participants met criterion A of the DSM-IV PTSD classification. The mean number of reported traumatic events was 12.6 (s.d.=2.9). The most frequently reported events were: combat situation $(100 \%)$; lack of food and water $(100 \%)$; lack of shelter and loss of goods $(97 \%)$; and near-death experience (95\%). The item 'brainwash' was not applicable
Table 2 Experienced traumatic events as measured by the Harvard Trauma Questionnaire (HTQ)

\begin{tabular}{|c|c|c|c|c|}
\hline & $\begin{array}{c}\text { Total } \\
(n=206) \\
\%\end{array}$ & $\begin{array}{l}\text { Intervention } \\
\qquad \begin{array}{c}(n=66) \\
\%\end{array}\end{array}$ & $\begin{array}{c}\text { Control } \\
(n=7 I) \\
\%\end{array}$ & $\begin{array}{c}\text { Non-case } \\
(n=69) \\
\%\end{array}$ \\
\hline \multicolumn{5}{|l|}{ Original HTQ items } \\
\hline Combat situation & 100 & 100 & 99 & 100 \\
\hline Lack of food/water & 100 & 100 & 100 & 99 \\
\hline No shelter & 97 & 95 & 97 & 97 \\
\hline Close to death & 95 & 97 & 94 & 94 \\
\hline Lack of medical care & 86 & 91 & 86 & 83 \\
\hline Forced separation & 81 & 85 & 80 & 77 \\
\hline Unnatural death (family/friends) & 69 & 65 & 68 & 75 \\
\hline Lost or kidnapped & 64 & 62 & 66 & 64 \\
\hline Physical torture & 56 & 58 & 55 & 57 \\
\hline Murder of family/friends & 55 & 61 & 54 & 52 \\
\hline Serious injury & 15 & 17 & 15 & 12 \\
\hline Imprisoned & II & 14 & 7 & 12 \\
\hline Murder of strangers & 3 & 0 & 6 & 3 \\
\hline Sexual abuse' & I & 2 & 0 & I \\
\hline Brainwashed & 0 & 0 & 0 & 0 \\
\hline \multicolumn{5}{|l|}{ Added items } \\
\hline Loss of goods & 97 & 98 & 96 & 97 \\
\hline Lost or kidnapped family members & 75 & 77 & 76 & 72 \\
\hline Ambushed & 60 & 61 & 63 & 55 \\
\hline Threatened with execution & 45 & 52 & 51 & 33 \\
\hline Threatened with torture & 27 & 23 & 30 & 29 \\
\hline Threatened with having to watch torture & 22 & 20 & 24 & 23 \\
\hline
\end{tabular}

I. $37 \%$ of participants responded that they had witnessed sexual violence. 
Table 3 Symptoms as measured at baseline and post-intervention

\begin{tabular}{|c|c|c|c|c|c|c|}
\hline & \multicolumn{2}{|c|}{ Baseline } & \multicolumn{2}{|c|}{ Post-intervention } & \multicolumn{2}{|l|}{$t$} \\
\hline & Mean & s.d. & Mean & s.d. & & \\
\hline \multicolumn{7}{|l|}{ Intervention group $(n=63)$} \\
\hline Psychiatric symptoms (SRQ-20) & 8.79 & 3.9 & 7.16 & 3.5 & 4.26 & $* * *$ \\
\hline Post-traumatic stress symptoms (total) & 49.61 & 6.3 & 40.08 & 9.6 & 10.41 & $* * *$ \\
\hline Intrusion & 16.17 & 2.7 & 10.78 & 4.4 & 10.26 & $* * *$ \\
\hline Avoidance & 17.43 & 3.1 & 15.85 & 3.3 & 3.82 & $* * *$ \\
\hline Hyperarousal & 16.16 & 3.38 & 13.77 & 4.3 & 5.21 & $* * *$ \\
\hline Nightmare impact (NITE total) $(n=56)^{\prime}$ & 8.86 & 4.1 & 6.25 & 4.4 & 3.63 & $* *$ \\
\hline \multicolumn{7}{|l|}{ Control group $(n=68)$} \\
\hline Psychiatric symptoms (SRQ-20) & 9.06 & 3.9 & 7.29 & 3.1 & 4.51 & $* * *$ \\
\hline Post-traumatic stress symptoms (total) & 49.29 & 6.6 & 40.70 & 8.7 & 8.97 & $* * *$ \\
\hline Intrusion & 16.40 & 2.3 & 11.64 & 4.2 & 8.97 & $* * *$ \\
\hline Avoidance & 16.63 & 2.9 & 15.59 & 3.1 & 2.87 & $* *$ \\
\hline Hyperarousal & 16.21 & 3.6 & 13.61 & 4.1 & 5.47 & $* * *$ \\
\hline Nightmare impact (NITE total) $(n=56)$ & 9.32 & 3.3 & 6.54 & 4.6 & 4.18 & $* * *$ \\
\hline \multicolumn{7}{|l|}{ Non-case (no intervention) $(n=67)$} \\
\hline Psychiatric symptoms (SRQ-20) & 4.49 & 3.0 & 4.07 & 2.5 & 1.22 & NS \\
\hline Post-traumatic stress symptoms (total) & 32.00 & 5.9 & 32.31 & 5.8 & -0.36 & NS \\
\hline Intrusion & 9.21 & 4.3 & 7.38 & 3.2 & 3.27 & $* *$ \\
\hline Avoidance & $|2.5|$ & 2.0 & 14.04 & 1.7 & -4.79 & $* * *$ \\
\hline Hyperarousal & 10.31 & 2.3 & 11.00 & 3.1 & -1.76 & NS \\
\hline Nightmare impact (NITE total) $(n=40)$ & 5.63 & 4.1 & 5.05 & 3.8 & 0.59 & NS \\
\hline
\end{tabular}

SRQ-20, Self-Report Questionnaire (neurosis sub-scale); NITE, Nocturnal Intrusions after Traumatic Experiences questionnaire.

I. Nightmare impact was calculated if anxiety dreams were reported at baseline or post-intervention measurements. $* * P<0.01 ; * * * P<0.001$.

in these samples, and very few participants testified to having been a victim of rape or sexual abuse. Although $37 \%$ admitted to having witnessed and $48 \%$ to having heard about sexual violence, only $2 \%$ reported having been raped or sexually abused.

When the three groups (intervention, control and non-case) were compared, no significant differences were found between them. All participants experienced more or less the same traumatic events, and the degree of their exposure was determined by the number of years living within the war zones, which was about the same for all groups in this study.

Comparison of the most frequently reported events in relation to gender revealed significant differences between men and women. The mean number of traumatic experiences for men (13.3) was higher than for women (11.8) $(t=3.77$, d.f. $=204, P=0.0002$ ).

\section{Psychiatric and post-traumatic stress symptoms at baseline and post-intervention}

Table 3 shows the results of the baseline and post-intervention measurements on the various symptom scales and for the three groups (intervention, control and non-case). In all measurements, postintervention scores were significantly lower in the intervention and control groups compared with each individual's baseline scores. The pattern of differences between the two measurements appeared very much the same for the intervention and the control groups. The non-case group showed significant changes on the intrusion and avoidance sub-scales, but in a different (more symptomatic) direction on the avoidance sub-scale when compared with the other two groups.

The possibility of an interaction effect between the intervention and control groups and the factor 'gender' on the dependent variables (total psychiatric symptoms scale, PTSD symptom scales and the nightmare impact scale) was analysed by a two-way multivariate analysis of covariance with repeated measurements. 'Total number of violent experiences' was used as a covariable. Between participants, significant effects turned out to be related to the total number of violent experiences (showing more symptoms if there were more events: $F=3.67$, d.f. $=$ $5,115, P=0.004$ ) and to gender (in general more symptoms were reported by women, but men did report more intrusion symptoms: $F=6.71$, d.f. $=5,115, P=0.00002$ ).

Differences between baseline and postintervention measurements were significant (post-intervention scores were lower: $F=2.91$, d.f. $=5,115, P=0.016$ ) but there was no interaction effect with the intervention factor or with any of the other factors. Univariate analyses of the differences between the baseline and postintervention measurements revealed the largest effect to be located in the scores of the intrusion sub-scale $(F=9.75$, d.f. $=1,119, P=0.002$ ).

If an interaction factor between gender and the covariable (number of violent experiences) was added to the multivariate model, this interaction effect was found to be significant $(F=3.33, \quad$ d.f. $=5,112$, $P=0.008$ ) but did not result in significant interaction effects related to the intervention. However, in the univariate analysis of the SRQ scale a complex four-way interaction (including gender, number of events and intervention) approached significance $(F=3.65$, d.f. $=1,116, P=0.059)$.

\section{Symptoms at follow-up}

The 11-month follow-up symptom measurements were compared with the post-intervention measurements. Taking intervention and control groups together, scores on the avoidance sub-scale were a bit higher (not significantly) but all other scales showed lower levels. Paired-sample $t$-tests showed significantly lower levels for symptoms measured by the SRQ $(t=2.52$, d.f. $=130, P=0.013)$ and for scores on the hyperarousal sub-scale $(t=2.91$, d.f. $=119, P=0.004)$.

Possible follow-up intervention effects were evaluated by using the same primary multivariate model as was used in the analysis of the post-intervention effects, with baseline and follow-up measurements 
as the dependent variables. Significant effects turned out again to be related to the total number of violent experiences $(F=3.92$, d.f. $=5,108, P=0.003)$, to gender $(F=5.22$, d.f. $=5,108, P=0.0002)$ and to the differences between baseline and follow-up measurements ( $F=4.76$, d.f. $=$ $5,108, P=0.001)$. In contrast with the analysis of the post-intervention results, some interaction effects showed statistical significance. If the factor 'time' denotes 'baseline $v$. follow-up' measurement, then a two-way interaction effect was related to the factor gender (time $\times$ gender: $F=1.22$, d.f. $=5,108$, $P=0.036)$. A three-way interaction effect approached significance (time $\times$ gender $\times$ intervention: $F=2.21$, d.f. $=5,108, P=0.058$ ).

Univariate analyses showed that these effects were primarily associated with the SRQ scale (time $\times$ gender $\times$ intervention: $F=4.78$, d.f. $=1,112, P=0.031$ ), the avoidance sub-scale (time $\times$ intervention: $F=5.14$, d.f. $=1,112, P=0.025$ ), and the NITE total score (time $\times$ gender $\times$ intervention: $F=3.37$, d.f. $=1,112, P=0.069$ ).

To illustrate this interaction pattern, Fig. 1 shows outcomes resulting from reported experiences of anxiety dreams (as measured by the NITE questionnaire) for men $v$. women during baseline, postintervention and 11-month follow-up. If proportions of anxiety dreams were calculated for men (respectively control $v$. intervention group: $84 \%, 72 \%$; $64 \%, 64 \%$; $53 \%, 62 \%), \chi^{2}$ tests did not reveal significant differences between the two groups. The same calculations for women showed a different pattern (respectively control $v$. intervention group: $82 \%, 78 \% ; 69 \%$, $58 \% ; 64 \%, 35 \%)$ and $\chi^{2}$ tests showed significance of the follow-up measurement $\left(\chi^{2}=4.90\right.$; d.f. $\left.=1, P=0.027\right)$. The differences between the above-mentioned proportions (control minus intervention group) as found for men and women are the numbers presented in Fig. 1.

\section{DISCUSSION}

The aim of this study was to evaluate the effectiveness of a brief and simple application of a testimony intervention procedure in reducing post-traumatic stress symptoms in a rural population of a warstricken part of Mozambique. Potential healing effects of the testimony method are attributed to the opportunity for the survivor to reconstruct a harmful period, to find meaning in the experience or to be able to talk about it, and to learn and teach

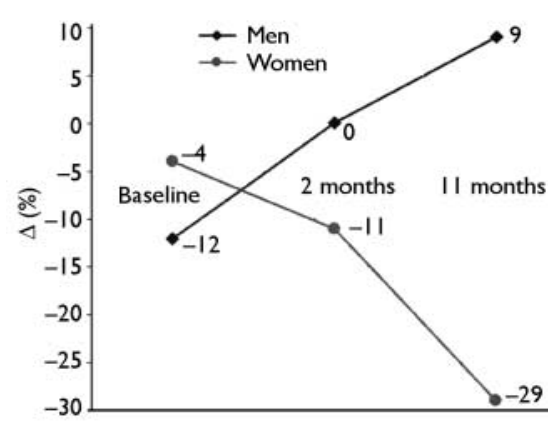

Fig. I Differences in the percentages of reported anxiety dreams $(\Delta)$ between intervention $v$. control group for men and women at baseline, postintervention ( 2 months) and II-month follow-up.

Anxiety dreams were measured by the Nocturnal Intrusions after Traumatic Experiences

questionnaire. Percentages of anxiety dreams as reported in the control group were subtracted from those reported in the intervention group. Negative numbers indicate fewer anxiety dreams in the intervention group and positive numbers indicate fewer anxiety dreams in the control group.

what it means to survive political violence. The experience of telling the trauma story to others (i.e. the transformation of the private experience into a public one) can function as a real psychological alleviation mechanism. Although some authors have stated that testifying is a universal practice, there are still few publications describing its benefits or limitations as a treatment modality (Agger \& Jensen, 1990).

Comparing our intervention with other studies using testimonies as an intervention technique, the social, cultural and political contexts were different. The intervention was not situated in a specialised trauma centre but in the households of the trauma survivors, and construction of the testimonies was not related to expectations of obtaining possible justice and reparation (Agger \& Jensen, 1990; Kaminer et al, 2001).

The use of a controlled trial design in a community setting produced interesting and unexpected outcomes. Our findings show a significant reduction in symptoms but, unexpectedly, the effect was observed in both the intervention and the control group. Only the 11-month follow-up measurements showed some indications of positive effects that could be related to the intervention, and then only in the group of female participants. Not finding clear, robust intervention effects is especially relevant against the background of an ongoing debate regarding the validity of such constructs as PTSD in non-Western settings and the relevance of specific treatments used for PTSD. Summerfield (1999) has raised some fierce criticisms on programmes introducing Western-based PTSD treatments in war-stricken non-Western communities. Like any other community, poor African populations deserve programmes of psychiatric intervention based on sound evidence of effectiveness and feasibility, proven in their own cultural settings.

The reduction of symptoms in this study is generally consistent with previous non-controlled trials using the same method (Weine et al, 1998). Although also consistent with other exposure studies promoting fear activation and/or emotional engagement (Foa \& Riggs, 1995), the mentioned unexpected symmetry between intervention and control group measurement is still in need of some explanation. One such explanation could be that the passage of time plays a role and symptom levels gradually decrease, irrespective of any intervention technique. However, a prior study in the same population (a year before our study) did report high symptom levels comparable with our baseline measures (Schreuder et al, 2001). Such a stable symptom level during a relatively long period makes a relation between the time factor and the 'sudden' drop at the end of the 8 weeks of the study period rather improbable. Another explanation could be that, although the intervention was designed as a controlled trial and was individually oriented, it did in fact involve the whole community (intervention, control, non-case and other community members). A great deal of uncontrolled interaction and communication between all community members was generated and this may have produced a domino effect. If such community interaction augments intervention effects or is a prerequisite for them to happen, then it will be even harder to detect the influence of an intervention in a controlled way. Also, the fact that for most participants the intervention comprised only one session could explain the difficulties in detecting robust effects.

Our observations suggest that telling the trauma story and assisting trauma survivors to build a narrative of the traumatic events helped them to provide a framework for traumatic experiences. This impression is consistent with findings showing that the organisation of disorganised and fragmented memories may be an important vehicle for a successful treatment and 
recovery (Foa, 1997). Memories of war experiences in Gorongosa make up part of each individual's history and if there is something that could be described as both an individual and communal identity it is 'trauma survivor'. The careful reconstruction of the traumatic memories and the verbalisation of these memories to an outsider allowed the trauma survivors in Gorongosa to explore more about their identity, not as victims but, more importantly, as survivors. People clearly recognised the importance of this and were eager to give their testimony during the study (although this wish could not always be honoured if it was incompatible with the controlled design of the study).

\section{Feasibility of the intervention method}

Although the study did not show a clear treatment effect, the question of feasibility of the testimony method if applied in a poor, rural and illiterate African community can still be of value because there are not many options available to help a traumatised population to recover mental health in such circumstances. Our experiences suggest that when all the members of a community have gone through more or less the same traumatic experiences the process of building the survivor, as opposed to the victim, identity is meaningful through the intervention of an outsider who is prepared to go into the details of the traumatic experiences. It is not a simple matter of narration of a past experience but a careful look into different aspects of these memories. This process can be reinforced only through a foreign listener, because within the society no one really wants to know about the other person's experiences. Often the common understanding that there is no need to hear one another's experiences because everyone already 'knows' what has happened to each other is implicitly shared. This may not always be the truth; in some cases, our intervention provided a situation for family members to learn about the traumatic experiences of other relatives that had never been shared before. Several of the participants declared that the availability of a written testimony would serve to inform and teach future generations about the events that took place, in order to prevent another war occurring. In this sense, the written story can be an added value to the limitations of the oral tradition, which is to some extent more vulnerable to losses in every transition from one generation to the next.

From a political and human rights perspective it should be mentioned that, during this study, participants never had the expectation that their testimonies would result in reparation for either side in the conflict. Nevertheless, we got the impression that involvement in the study greatly released participants from feelings of guilt about not having managed to escape from the war zones, like many other Mozambicans who fled to neighbouring countries. The process of giving testimony also changed perceptions that the peace settlement had launched them into an anonymous and marginal state. Seven years after the end of the civil war, according to their collective memories, it was the first time that such a project had been carried out in order to listen to their dramatic stories, to reconstruct their narratives and, in doing so, enrich the meaning of being a war survivor.

\section{Feasibility of the instruments used}

Post-traumatic stress disorder research presents many challenges when it has to be carried out in non-Western societies. To date, there are few published ethnocultural studies of PTSD concerned with assessment issues, in spite of the fact that cultural sensitivity in assessment procedures may be a major factor in the determination of PTSD rates and clinical features (Marsella et al, 1996). The standardised way in which the participants were expected to give their answers proved to be problematic in our study. In addition, it was very difficult to find meaningful words or phrases in the local language for several other concepts related to 'affect', 'remembering', 'hearing' and 'thinking'. Owing to space limitations, not all transcultural challenges can be discussed here but they can be provided upon request.

\section{Limitations of this study}

To carry out a controlled designed study in a community setting proved to be a very complicated task, which had several limitations and also posed an ethical problem. The testimony-tellers participated in a positive way but they could not understand the reason for the existence of a control group. The interviewer (V.I.) was confronted several times with questions related to the fact that only a selected group was receiving the intervention.
Another limitation is related to the standardised way in which the intervention had to be delivered. Each participant was requested to narrate only one experience that was overwhelming in comparison with his or her other traumatic experiences. In some cases, the participants wanted to recount more than one traumatic experience and they could not be prevented from doing so. Also, if participants easily accepted narrating only one traumatic experience, the content of their narrative often encompassed different experiences. In such circumstances, before the process of a narrative reconstruction could begin, we had to go through three phases. First, the trauma survivor recollected the selected traumatic experience. Second, we began to separate overlapping stories into only one narrative and we placed them in their specific context. Third, the interviewer gave an overview of the different events to the trauma survivor, who then was able to trace one of the experiences so that the reconstruction of one narrative could really begin. This preparation phase was important; it provided a safe basis on which the narrative reconstruction could take place.

Participation in agricultural activities was a communal activity regulated by a cycle, some of the phases of which were possibly related to the prevalence of reexperiencing symptoms in specific periods of the year. For instance, involvement in harvest activities could be a confounding factor that is in need of a more thorough investigation.

Future trials can possibly improve on the study design in several ways: by extending the intervention to more sessions in order to increase the impact of the intervention; by introducing a control condition in which attention to the participants is given by offering a discussion of actual problems; or by selecting two comparable but separate regions, one control and one intervention region.

Nevertheless, in spite of the limitations of the study, the outcomes of this exploration may open new avenues for more comprehensive research into the type and nature, quality and availability of resources at the community level that may play a key role in trauma recovery in this sociocultural setting (Igreja, 2003). Such a scientific enquiry could provide muchneeded answers to the question of how to organise access to mental health help for trauma survivors in non-Western countries. 


\section{REFERENCES}

Agger, I. \& Jensen, S. (1990) Testimony as ritual and evidence in psychotherapy for political refugees. Journal of Traumatic Stress, 3, II5-130.

American Psychiatric Association (1994) Diagnostic and Statistical Manual of Mental Disorders (4th edn) (DSM-IV). Washington, DC: APA.

Bhagwanjee, A., Parekh, A., Paruk, Z., et al (1998) Prevalence of minor psychiatric disorders in an adult African rural community in South Africa. Psychological Medicine, 28, ||37-1147.

Cienfuegos, A. \& Monelli, C. (1983) The testimony of political repression as a therapeutic instrument. American Journal of Orthopsychiatry, 53, 43-5I.

de Girolamo, G. \& McFarlane, A. (1996) The epidemiology of PTSD: a comprehensive review of the international literature. In Ethnocultural Aspects of Posttraumatic Stress Disorder: Issues, Research, and Clinical Applications (eds A. J. Marsella, M. J. Friedman, E. T. Gerrity, et al), pp. 33-85. Washington, DC: American Psychological Association.

Deshpande, S. N., Sundaram, K. R. \& Wig, N. N. (1989) Psychiatric disorders among medical in-patients in an Indian hospital. British Journal of Psychiatry, 154, 504-509.

Foa, E. (1997) Psychological processes related to recovery from trauma and an effective treatment for PTSD. In Psychobiology of Posttraumatic Stress Disorder (eds R. Yehuda \& A. McFarlane), pp. 4I0-424. New York: NYAS.

Foa, E. \& Riggs, D. (1995) Posttraumatic stress disorder following assault: theoretical considerations and empirical findings. Current Directions, 4, 6I-65.

Foa, E., Riggs, D., Massie, E., et al (1995) The impact of fear activation and anger on the efficacy of exposure treatment for PTSD. Behavioural Therapy, 26, 487-499.

Harding, T. W., de Arango, M. V., Baltazar, J., et al (1980) Mental disorders in primary health care: a study of their frequency and diagnosis in four developing countries. Psychological Medicine, 10, 23I-24I.

Hovens, J., Bramsen, I. \& van der Ploeg, H. (200I) Handleiding bij de Zelfinventarisatievragenlijst

Posttraumatische Stressstoornis (ZIL). Lisse: Swets \& Zeitlinger.

Igreja, V. (2003) Why are there so many drums playing until dawn? Exploring the role of gamba spirits and healers in the post-war recovery period in Gorongosa, Central Mozambique. Transcultural Psychiatry, 40 459-487.

Kaminer, D., Stein, D. J., Mbanga, I., et al (200I) The Truth and Reconciliation Commission in South Africa: relation to psychiatric status and forgiveness among survivors of human rights abuses. British Journal of Psychiatry, 178, 373-377.

Kleijn, W., Hovens, J. \& Rodenburg, J. (200I) Posttraumatic stress symptoms in refugees: assessments with the Harvard Trauma Questionnaire and the Hopkins Symptom Checklist-25 in different languages. Psychological Reports, 88, 527-532.

Marsella, A. J., Friedman, M. J. \& Spain, E. H. (1996) Ethnocultural aspects of PTSD: an overview of issues

\section{CLINICAL IMPLICATIONS}

- The application of a simple version of the testimony method in a war-stricken African agricultural community did not show a clear intervention effect. There were indications of reduced levels of anxiety dreams in women at follow-up.

- Although standardised instruments for measuring psychiatric symptoms had to be adapted, they nevertheless proved to be feasible and reliable.

- Introduction of the testimony method in a relatively small and isolated rural community was feasible and associated with the decrease of reported psychiatric symptoms.

\section{LIMITATIONS}

Although designed as a case-control study, the local circumstances in this rural community interfered substantially with this intention.

- The instruments were applied as semi-structured interviews instead of selfreported measurements because of the illiteracy of the participants.

- Application of the testimony method involved only one session for most participants.

VICTOR IGREJA, MA, Associação Esperança Para Todos, Gorongosa, Mozambique; WIM C. KLEIIN, MSc, Centrum '45, Oegstgeest, and Leiden University Medical Centre, Medical Psychology, Leiden; BAS J. N. SCHREUDER, PhD, AMC/De Meren, Amsterdam, and UMCSt Radboud, Nijmegen; JANIE A. VAN DIJK, MSc, Centrum '45, Oegstgeest; MARGOT VERSCHUUR, MSc, Leiden University, Department of Psychology, Leiden, The Netherlands

Correspondence: Victor Igreja, c/o Wim Kleijn, Centrum '45, Rijnzichtweg 35, 2342 AXOegstgeest, The Netherlands. Tel: 0031 7I 5I55242; e-mail: vigreja@yahoo.com

(First received 10 March 2003, final revision 17 July 2003, accepted 31 July 2003)

and future directions. In Ethnocultural Aspects of Posttraumatic Stress Disorder: Issues, Research, and Clinical Applications (eds A. J. Marsella, M. J. Friedman, E. T. Gerrity, et al), pp. 105-129. Washington, DC: American Psychological Association.

Mollica, R., Caspi-Yavin, Y., Lavelle, J., et al (1996) Harvard Trauma Questionnaire (HTQ): Manual of Cambodian, Laotian, and Vietnamese Versions. TORTURE - Quarterly Journal on Rehabilitation of Torture Victims and Prevention of Torture (suppl. I).

Schreuder, B., Kleijn, W. \& Rooijmans, H. (2000) Nocturnal re-experiencing more than forty years after war trauma. Journal of Traumatic Stress, 13, 453-463.

Schreuder, B., Igreja, V., van Dijk, J., et al (200I) Intrusive re-experiencing of chronic strife of war. Advances in Psychiatric Treatment, 7, 102-108.
Summerfield, A. (1999) A critique of seven assumptions behind psychological trauma programs in war-affected areas. Social Science and Medicine, $\mathbf{4 8}$ 1449-1462.

Van der Kolk, B., McFarlane, A. \& van der Hart, 0 . (1996) A general approach to treatment of posttraumatic stress disorder. In Traumatic Stress: The Effects of Overwhelming Experience on Mind, Body, and Society (eds B. Van der Kolk, A. McFarlane \& L. Weisaeth), pp. 417-440. New York: Guilford Press.

Weine, S., Kulenovic, A., Pavkovic, I., et al (1998) Testimony psychotherapy in Bosnian refugees: a pilot study. American Journal of Psychiatry, 155, 1720-1726.

World Health Organization (2002) World Report on Violence and Health Geneva: WHO. 